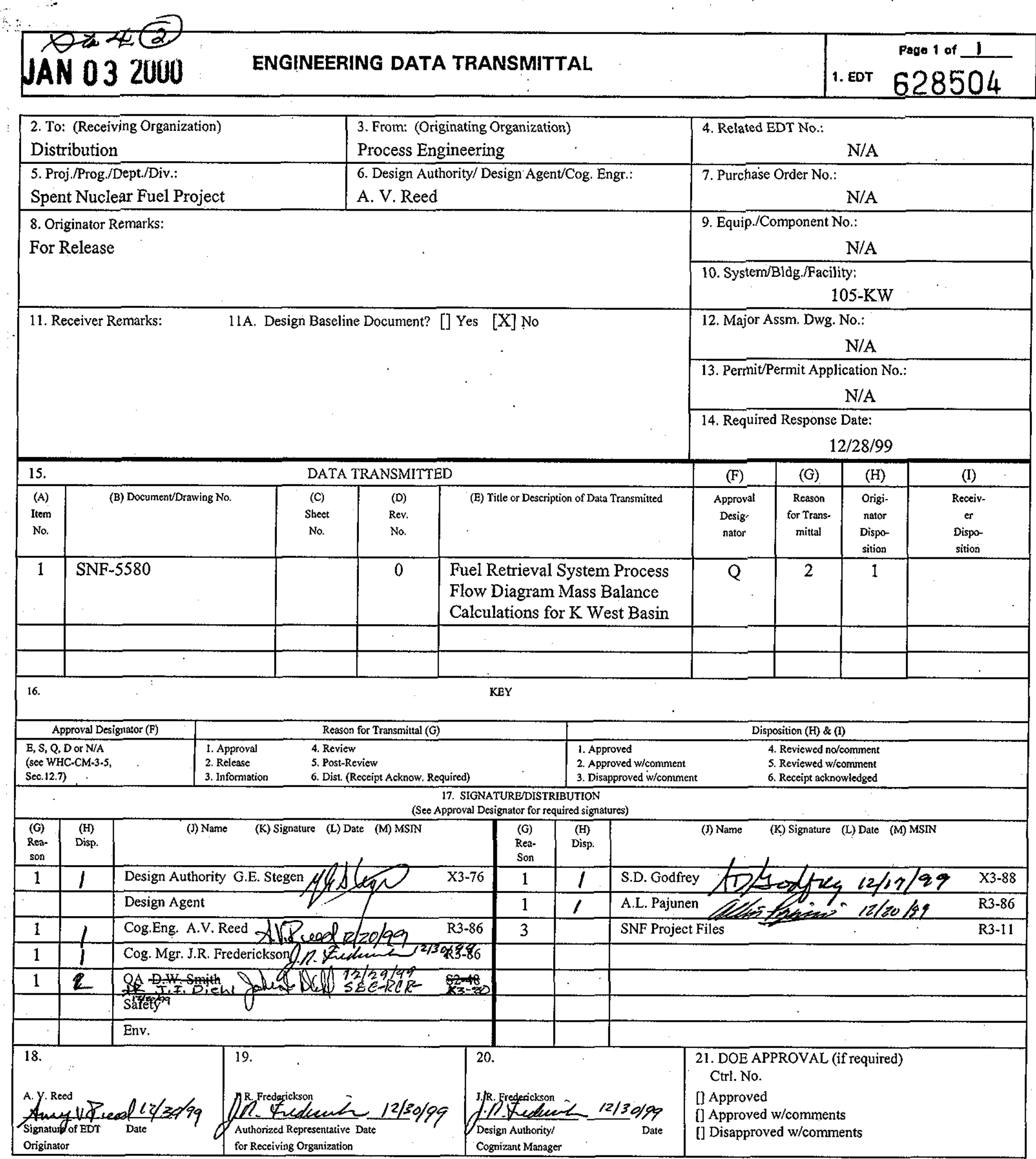

BD-7400-172-2 (05/96) GEF097 


\title{
FUEL RETRIEVAL SYSTEM PROCESS FLOW DIAGRAMS MASS BALANCE CALCULATIONS FOR K WEST BASIN
}

\author{
*A. V. Reed \\ Fluor Daniel Hanford, Richland, WA 99352 \\ U.S. Department of Energy Contract DE-AC06-96RL13200
}

EDT/ECN: 628504

UC: 510

Org Code: 87100

Charge Code: $105355 / \mathrm{A} 010$

B\&R Code: EW7040000

Total Pages: 19

Key Words: Process Flow Diagram, Mass Balance, Fuel Retrieval, KW Basin Calculations

Abstract: this calculation justifies the numbers used for the material balance on the process flow diagrams for the KW Basin Fuel Retrieval Subproject.

* Cogema Engineering, Inc.

TRADEMARK DISCLAIMER. Reference herein to any specific commercial product, process, or service by trade name, trademark, manufacturer, or otherwise, does not necessarily constitute or imply its endorsement, recommendation, or favoring by the United States Government or any agency thereof or its contractors or subcontractors.

Printed in the United States of America. To obtain copies of this document, contact: Document Control Services, P.O. Box 950, Mailstop H6-08, Richland WA 99352, Phone (509) 372-2420; Fax (509) 376-4989.
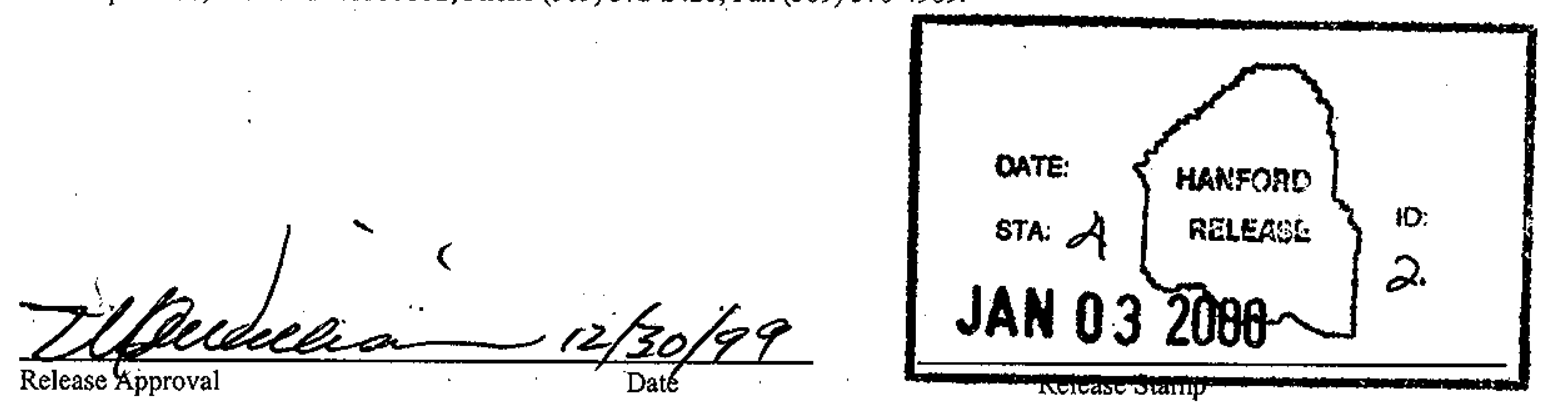
SNF-5580, Rev. 0

\section{Fuel Retrieval System PFD Mass Balance Calculations K West Basin}

Table of Contents

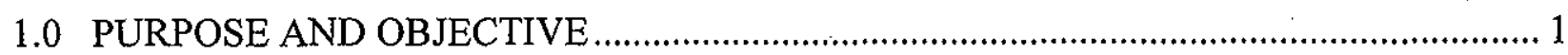

2.0 SUMMARY OF FINAL RESULTS AND CONCLUSIONS ........................................ 1

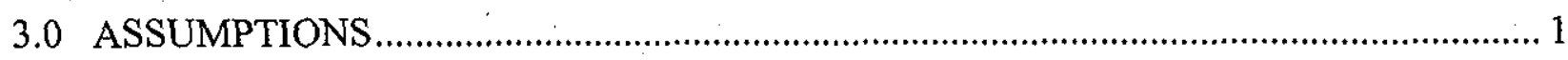

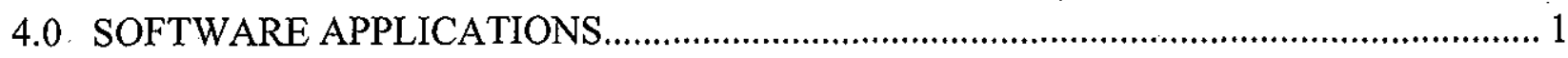

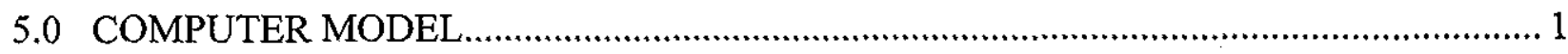

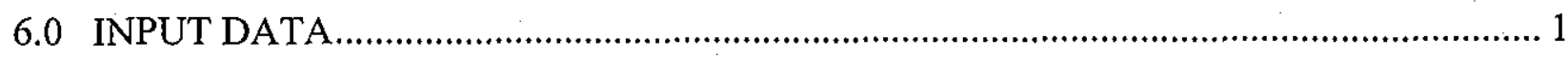

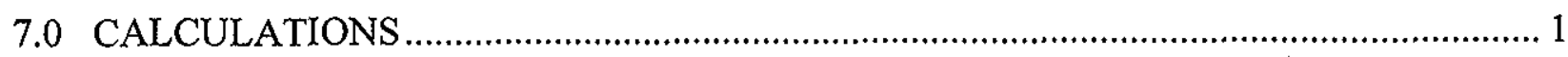

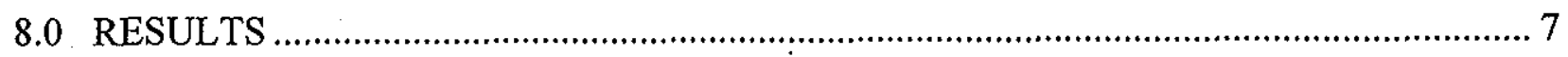

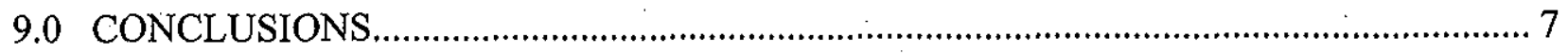

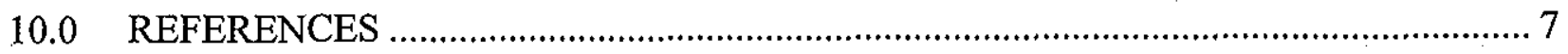

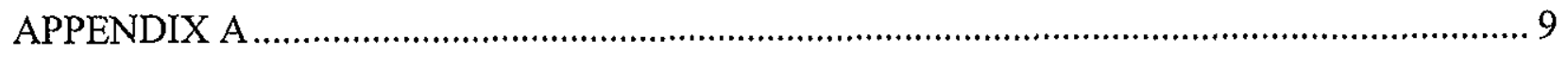

\section{List of Tables}

Table 1: Distribution of MK IV Fuel Assemblies in K Basins............................................... 1

Table 2: Distribution of MK IA Fuel Assemblies in K Basins ............................................... 2

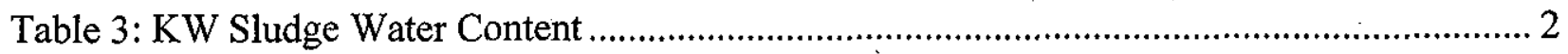




\section{Fuel Retrieval System PFD Mass Balance Calculations K West Basin}

\subsection{PURPOSE AND OBJECTIVE}

The purpose of these calculations is to develop the material balances that are documented in the FRS Process Flow Diagrams for future reference. The attached mass calculations were prepared in support of revising the fuel retrieval system process flow diagrams for the $105 \mathrm{~K}$ West Basin. The calculations refer to diagram H-1-81164.

\subsection{SUMMARY OF FINAL RESULTS AND CONCLUSIONS}

See appendix A for final results.

\subsection{ASSUMPTIONS}

See assumptions page in appendix A.

\subsection{SOFTWARE APPLICATIONS}

None used.

\subsection{COMPUTER MODEL}

Excel spreadsheet used to display material balance and verify hand calcualations.

\subsection{INPUT DATA}

See appendix $A$.

\subsection{CALCULATIONS}

\subsection{Average Masses of MK IV and MK IA Fuel Assemblies}

MK IV and MK IA fuels were manufactured in a variety of lengths (and masses). This calculation is an estimate of the average mass per fuel assembly according to the combined distribution of fuel in both the $\mathrm{KE}$ and $\mathrm{KW}$ Basins.

Per Table 3.1 of Reference 4:

Table 1: Distribution of MK IV Fuel Assemblies in K Basins

\begin{tabular}{|l|c|c|c|c|}
\hline MK IV Length & $\mathrm{E}$ & $\mathrm{S}$ & $\mathrm{A}$ & $\mathrm{C}$ \\
\hline Outer clad (kg) & 1.09 & 1.04 & 0.99 & 0.79 \\
\hline Inner clad (kg) & 0.55 & 0.52 & 0.50 & 0.40 \\
\hline Outer U (kg) & 16.0 & 15.0 & 14.1 & 10.5 \\
\hline Inner U (kg) & 7.48 & 7.03 & 6.62 & 4.94 \\
\hline Total kg per assembly & 25.12 & 23.59 & 22.21 & 16.63 \\
\hline \% of MK IV assemblies in K Basins & $78 \%$ & $10 \%$ & $7 \%$ & $5 \%$ \\
\hline
\end{tabular}

Average mass of a MK IV assembly is:

$0.78(25.12 \mathrm{~kg})+0.1(23.59 \mathrm{~kg})+0.07(22.21 \mathrm{~kg})+0.05(16.63 \mathrm{~kg})=24.34 \mathrm{~kg} /$ assembly 
Table 2: Distribution of MK IA Fuel Assemblies in K Basins

\begin{tabular}{|l|c|c|c|c|}
\hline MK IA Length & $\mathrm{E}$ & $\mathrm{M}$ & $\mathrm{T}$ & $\mathrm{F}$ \\
\hline Outer clad (kg) & 1.07 & 0.88 & 0.83 & 0.66 \\
\hline Inner clad (kg) & 0.66 & 0.54 & 0.51 & 0.40 \\
\hline Outer U (kg) & 13.8 & 11.1 & 10.4 & 7.85 \\
\hline Inner U (kg) & 6.84 & 5.49 & 5.12 & 3.90 \\
\hline Total kg per assembly & 22.37 & 18.01 & 16.86 & 12.81 \\
\hline \% of MK IA assemblies in K Basins & $0.03 \%$ & $87 \%$ & $10 \%$ & $3 \%$ \\
\hline
\end{tabular}

Average mass of a MK IA assembly is:

$0.0003(22.37 \mathrm{~kg})+0.87(18.01 \mathrm{~kg})+0.1(16.86 \mathrm{~kg})+0.03(12.81 \mathrm{~kg})=17.75 \mathrm{~kg} / \mathrm{assembly}$

Results of these calculations are used in H-1-81164 notes.

\subsection{KW wt \% water in canister sludge plus wash sludge}

Per Table 2-2 of Reference 4a:

Table 3: KW Sludge Water Content

\begin{tabular}{|c|c|c|c|}
\hline Sludge Type & $\begin{array}{l}\text { Volume of } \\
\text { Sludge } \\
\left(\mathrm{m}^{3}\right)\end{array}$ & $\begin{array}{l}\text { As-settled Sludge } \\
\text { Density } \\
\left(\mathrm{g} / \mathrm{cm}^{3}\right)\end{array}$ & $\begin{array}{c}\text { As-settled Sludge Solid } \\
\text { Content (g dry solids } / \mathrm{cm}^{3} \text { as- } \\
\text { settled sludge) }\end{array}$ \\
\hline${ }^{1}$ Canister Sludge & 1.01 & 2.68 & 2.053 \\
\hline $\begin{array}{l}{ }^{2} \text { Fuel Wash Internal } \\
\text { Sludge }\end{array}$ & 0.518 & 3.00 & 2.310 \\
\hline${ }^{2}$ Fuel Wash - Coating & 0.405 & 1.50 & 0.970 \\
\hline $\begin{array}{l}\text { 2Fuel Wash - Fuel } \\
\text { Pieces }\end{array}$ & 0.149 & 11.02 & 10.612 \\
\hline
\end{tabular}

${ }^{1}$ Corrosion products within the canister

${ }^{2}$ Sludge dislodged during processing due to the brittleness of irradiated uranium metal and the fractured state of the uranium within the breached fuel that is made up of three components: coating material, internal sludge, and fuel pieces.

Then, the wet weight of the sludge is $\left(2.68 \mathrm{MT} / \mathrm{m}^{3} \times 1.01 \mathrm{~m}^{3}\right)+\left(3.00 \mathrm{MT} / \mathrm{m}^{3} \times 0.518 \mathrm{~m}^{3}\right)+$ $\left(1.50 \mathrm{MT} / \mathrm{m}^{3} \times 0.405 \mathrm{~m}^{3}\right)+\left(11.02 \mathrm{MT} / \mathrm{m}^{3} \times 0.149 \mathrm{~m}^{3}\right)=6.5 \mathrm{MT}$

Then, the dry weight of sludge is $\left(2.053 \mathrm{MT} / \mathrm{m}^{3} \times 1.01 \mathrm{~m}^{3}\right)+\left(2.310 \mathrm{MT} / \mathrm{m}^{3} \times 0.518 \mathrm{~m}^{3}\right)+$ $\left(0.970 \mathrm{MT} / \mathrm{m}^{3} \times 0.405 \mathrm{~m}^{3}\right)+\left(10.612 \mathrm{MT} / \mathrm{m}^{3} \times 0.149 \mathrm{~m}^{3}\right)=5.244 \mathrm{MT}$

The amount of water is the difference between the wet and dry weights.

Water is $6.5 \mathrm{MT}-5.244 \mathrm{MT}=1.266 \mathrm{MT}$

The water is $1.266 \mathrm{MT} / 6.5 \mathrm{MT}=20 \mathrm{wt} \%$ of the wet sludge. 


\section{SNF-5580, Rev. 0}

This calculation forms the basis for the interstitial sludge water shown in Assumption 1 of $\mathrm{H}-1$ 81164.

\subsection{Estimated Volume of Gas per Canister in KW}

This estimate is the maximum gas volume in the canister and gas trap, which occurs in a Mark II canister. The estimate does not include any additional volume of gas in the canister barrel generated by the consumption of water in the uranium oxidation reaction. The volumes are based on the volume of inert gas initially charged to the canister at standard temperature and pressure.

The total volume of gas per barrel (max) in a Mark II canister is 1.46 liters per Reference 11.

The total volume of gas per gas trap in a Mark II canister is about 40 cubic inches ( 0.66 liters) per Drawing H-1-46215, Rev. 4, Sheet 4.

The total gas is the sum for the barrel and gas trap, and is 2.12 liters/barrel, which is 4.24 liters per canister.

\subsection{Discussion of KW Stream Calculations in H-1-81164}

\section{FW-1 Retrieved Canister to Staging}

Entries for this stream are the numbers of canisters and fuel elements per the drawing notes. The fuel isotopic activities and sludge data are calculated by the spreadsheet using the data in the $\mathrm{H}$ 1-81164 Assumption 1 table. The SPR fuel is not included in the spreadsheet calculations, except for showing the MCO baskets that will be used to load the SPR fuel into a single MCO.

\section{FW-2 Loose/Spilled Fuel Retrieved from Basin}

No fuel is estimated to be spilled by FRS.

\section{FW-3 Loose/Spilled Fuel Retrieved from Basin}

No fuel is estimated to be spilled by FRS.

FW-4 Loose/Spilled Fuel Retrieved from Basin

No fuel is estimated to be spilled by FRS.

\section{FW-5 Staged Canister to Decapping}

This stream is the same as FW-1.

\section{FW-6 Canister Gas to Offgas Treatment}

All canister gas is assumed to go to offgas treatment in this PFD, although some gas will be released directly to the basin. The volume of the gas is expanded in this stream to atmospheric pressure.

FW-7 Canister Lids to Debris Bin

There are two lids per canister in FW-5. 


\section{FW-8 Empty Debris Bin}

Assume 20 lids per debris bin. With a total of 3841 canisters, 2 lids per canister, a total of (3841 x $2=7682$ lids) divided by 20 lids per debris bin gives 385 debris bins.

\section{FW-9 Filled Debris Bin to Debris Staging}

The canister lids will go to debris staging. This stream is the sum of FW-8 and FW-7.

FW-10 Decapped Canister to Primary Cleaning

Same as FW-5 without the canister lids or the canister gas.

\section{FW-11 Empty Wash Basket to Primary Cleaning}

Assume baskets will be emptied once out of every 10 canisters processed. Total canisters $3841+$ 20 stuck fuel $=3861$ canisters processed. $10 \%$ of canisters processed is 386 baskets needed.

The frequency which the baskets will be emptied will depend on the rate at which they fill with debris therefore $10 \%$ is used for material balance purposes and this number may change depending on necessity during processing.

\section{FW-12 Empty Strainer Basket to Primary Cleaning}

One basket emptied per every twenty canisters processed. Total canisters $3841+20$ stuck fuel $=$ 3861 canisters processed. 5\% of canisters processed is 193 baskets used. Strainer baskets will be reused. The frequency which the baskets will be emptied will depend on the rate at which they fill, therefore $5 \%$ is used for material balance purposes and this number may change depending on necessity during processing.

\section{FW-14 Basin Water to Decapping and Primary Cleaning}

Stream is FW-15 less the sum of FW-77 and FW-78.

FW-15 Water/Sludge from Primary Cleaning and Decapping

All sludge from $\mathrm{FW}-1$ plus $150 \mathrm{gpm}$ over the 2 year processing period.

FW-16 Fuel Bits in PCM Strainer Basket to Sorting Assume this stream is $0.1 \%$ of fuel. Strainer basket hold approximately $78 \mathrm{~kg}$ of fuel bits per ref. 7.

FW-17 Canister Removed from Tipping Station

Sum of initial canisters in FW-1 plus 20 canister containing 2 barrels each that are recycled back. Assume only half of the barrels contain stuck fuel (one per canister). There are seven fuel assemblies in each barrel and two elements per assembly. 2 elements * 7 assemblies * 1 barrel * 20 canisters $=280$ elements of stuck fuel.

FW-18 Empty Canister to Debris Staging

Canisters without stuck fuel. FW-1 canisters less 20 stuck fuel canisters.

FW-19 Canister to Stuck Fuel Station 20 canisters with 10 barrels of stuck fuel.

FW-21 Empty Canister to Stuck Fuel Station 20 canisters. 
SNF-5580, Rev. 0

FW-24 Empty Canisters After Stuck Fuel Removal

20 canisters.

FW-25 Empty Canisters to Debris Staging from Stuck Fuel

20 canisters.

FW-26 Removed Stuck Fuel to Canister

Fuel from FW-19.

FW-28 Canister with Formerly Stuck Fuel to Primary Cleaning

Sum of streams FW-21 and FW-26.

FW-29 Fuel in Canister to Processing Table

All fuel except bits in PCM Strainer.

FW-30 Emptied Wash Basket

Same as FW-11. Note that wash baskets are reused.

FW-31 Fuel to Sorting

This stream is the same as FW-29 minus wash basket and canister.

FW-33 Basin Water to Secondary Cleaning and Suction Wand

$150 \mathrm{gpm}$ continuous over the 2 year process period.

FW-35 Water/Sludge from Secondary Cleaning /Suction Wand

Same as FW-33. There is no sludge anticipated.

FW-37 Debris from Sort Area to Debris Bin

Debris from sort area not calculated but the potential flow path is observed for processing. Any observed mass will be small compared to canister debris.

FW-39 Empty Debris Bin to Fuel Sorting Area

Debris from sort area not calculated but the potential flow path is observed for processing. Any observed mass will be small compared to canister debris.

FW-41 Filled Debris Bin to Debris Staging

Debris from sort area not calculated but the potential flow path is observed for processing. Any observed mass will be small compared to canister debris.

FW-43 Fuel Bits and Scrap to Scrap Basket

This stream is, by assumption, $4 \%$ of all fuel. It includes the bits from the PCM strainer basket and scrap from the sort area.

FW-45 Fuel Directly to MCO Basket Loading and Staging

Fuel that bypasses disassembly and inspection. FW-1 - [FW-43 + FW-47]. 
SNF-5580, Rev. 0

FW-47 Fuel to Disassembly

For process validation. This stream is the sum of one out of every ten canisters per ref. 12, section 4.2 .

FW-49 Disassembled Fuel to Inspection

Same as FW-47.

FW-51 Dirty Fuel to Staging for Secondary Cleaning

Not normally used.

FW-52 Empty Strainer Basket

Same as FW-12.

FW-59 Secondary Cleaned Fuel to Staging

Same as FW-51.

FW-61 Clean Fuel to Staging from Disassembly/Inspection

Same as FW-49.

FW-63 Fuel to MCO Fuel Basket

$85 \%$ of all fuel. See assumption 18 of drawing H-1-81164.

FW-65 Filled MCO Basket to Verification

Assume 6 baskets for SPR Fuel. MK IV fuel loaded to capacity of 54 assemblies per fuel basket, and MK IA fuel loaded to capacity of 48 assemblies per basket per ref. 5 .

FW-67 Filled MCO Fuel Basket to Queue

Same as FW-65.

FW-69 Damaged Fuel to Scrap Basket

This stream is $11 \%$ of all fuel. By assumption 19 , scrap is $15 \%$ of all fuel. By assumption 26 , $4 \%$ is already separated in FW-43. $15 \%-4 \%=11 \%$.

FW-71 Scrap Basket to Fuel Bits Loading

$11 \%$ of all fuel, but the number of baskets is sufficient to hold $15 \%$ of all fuel at scrap basket loading limits.

FW-73 Filled Scrap Basket to Verification

$15 \%$ of all fuel. Number of baskets same as FW-71.

FW-75 Filled Scrap Basket to MCO Basket Queue

Same as FW-73.

FW-76 Fuel Cleaning Water to Equipment Wash Station

Intermittent flow of $5 \mathrm{gpm}$. Assume $20 \mathrm{~min} /$ canister for equipment wash.

FW-77 Fuel Cleaning Water to Primary Cleaning

Intermittent flow of $50 \mathrm{gpm}$ assume for 20 minutes per canister. 
FW-78 Fuel Cleaning Water to Decapping Station

Intermittent flow of $25 \mathrm{gpm}$ for decapping assume $10 \mathrm{~min} /$ canister.

IC-016 Basin Water

Sum of FW-14 and FW-33.

IC-017 Water/Sludge to IWTS from PCM/Decapping

Same as FW-15.

IC-022 Debris to Debris Removal

Sum of FW-25, FW-18, and FW-41.

IC-029 Oversize Fuel Bits from Sludge Removal

None anticipated.

IC-080 Debris Bin to Debris Removal

Same as FW-9.

IC-089 Empty MCO Fuel Basket

Baskets from FW-67.

IC-091 Fuel Cleaning Water to Primary Cleaning

This stream is the sum of FW-77, FW-78, and FW-76.

IC-127 Empty Scrap Basket

Number of scrap baskets from FW-75.

IC-197 Loaded Basket to MCO Loading

Sum of FW-75 and FW-67.

IC-198 Contaminated Water from Secondary Cleaning/Suction Wand to IWTS

Same as stream FW-35.

\subsection{RESULTS}

Results of the calculations are tabulated in Drawing H-1-81164.

\subsection{CONCLUSIONS}

Drawing H-1-81164 reflects the current processing strategy and configuration of the Fuel Retrieval Subproject.

\subsection{REFERENCES}

1. WHC-S-0461, Specification for Design of the SNF Project Fuel Retrieval Subproject, Rev. 0, G. R. Waymire, July 8, 1996, as amended by Engineering Change Notices 191405 (7/8/96), $191406(8 / 14 / 96), 631388(11 / 14 / 96)$, and 640507 (4/28/97). 
2. HNF-SD-SNF-TI-015, Spent Nuclear Fuel Project Technical Databook, Rev. 6, M. A. Reilly, October 23, 1998.

3. HNF-SD-SNF-TI-053, K Basins Sludge Inventory Composition, Rev. 0, M. J. Packer, January 30, 1998.

4. HNF-SD-SNF-TI-009, 105-K Basin Material Design Basis Feed Description for Spent Nuclear Fuel Project Facilities, Volume 1, Fuel, Rev. 2, M. J. Packer, November 4, 1999.

5. 4a. HNF-SD-SNF-TI-009, 105-K Basin Material Design Basis Feed Description for Spent Nuclear Fuel Project Facilities, Volume 2, Sludge, Rev, 2, K. L. Pearce, S. C. Klimper, T. A. Flament, September 2, 1998.

6. HNF-SD-SNF-CN-012, Estimated Fuel Inventory Loaded in Fuel and Scrap Baskets, Rev. 0, A. L. Pajunen, January 5, 1997.

7. HNF-SD-SNF-PAP-003, Fuel Retrieval system Process Validation Plan, Rev. 0, E. J. Shen, April 28, 1997.

8. HNF-SD-SNF-CSER-010, Criticality Safety Evaluation Report for the K Basin Fuel Retrieval Subproject, Rev. 1, S. F. Kessler and S. H. Peck, September 24, 1999.

9. WHC-SD-SNF-TI-016, Rev. 0-A, Development of Design Capacity for SNF Project Systems, A. L. Pajunen, July 21, 1997.

10. HNF-SD-SNF-TI-048, Analysis of Water from $K$ West Basin Canisters (Second Campaign), D. J. Trimble, March 1997.

11. HNF-SD-SNF-TI-049, Analysis of K West Basin Canister Gas, D. J. Trimble, March 1997.

12. WHC-SD-SNF-ANAL-008, Data Analysis of Gas and Liquid from $K$ West Basin Fuel Canisters; 1995 Samples, Rev. 0, page 70, May 1996.

13. SNF-4331, System Design Description for the Fuel Retrieval System (70.1), Rev. 0, B. D. Groth, July 12, 1999. 
SNF-5580, Rev. 0

Appendix A

MS Excel Spreadsheet Calculations

And Formulas Used to Develop

Drawing H-1-81164 


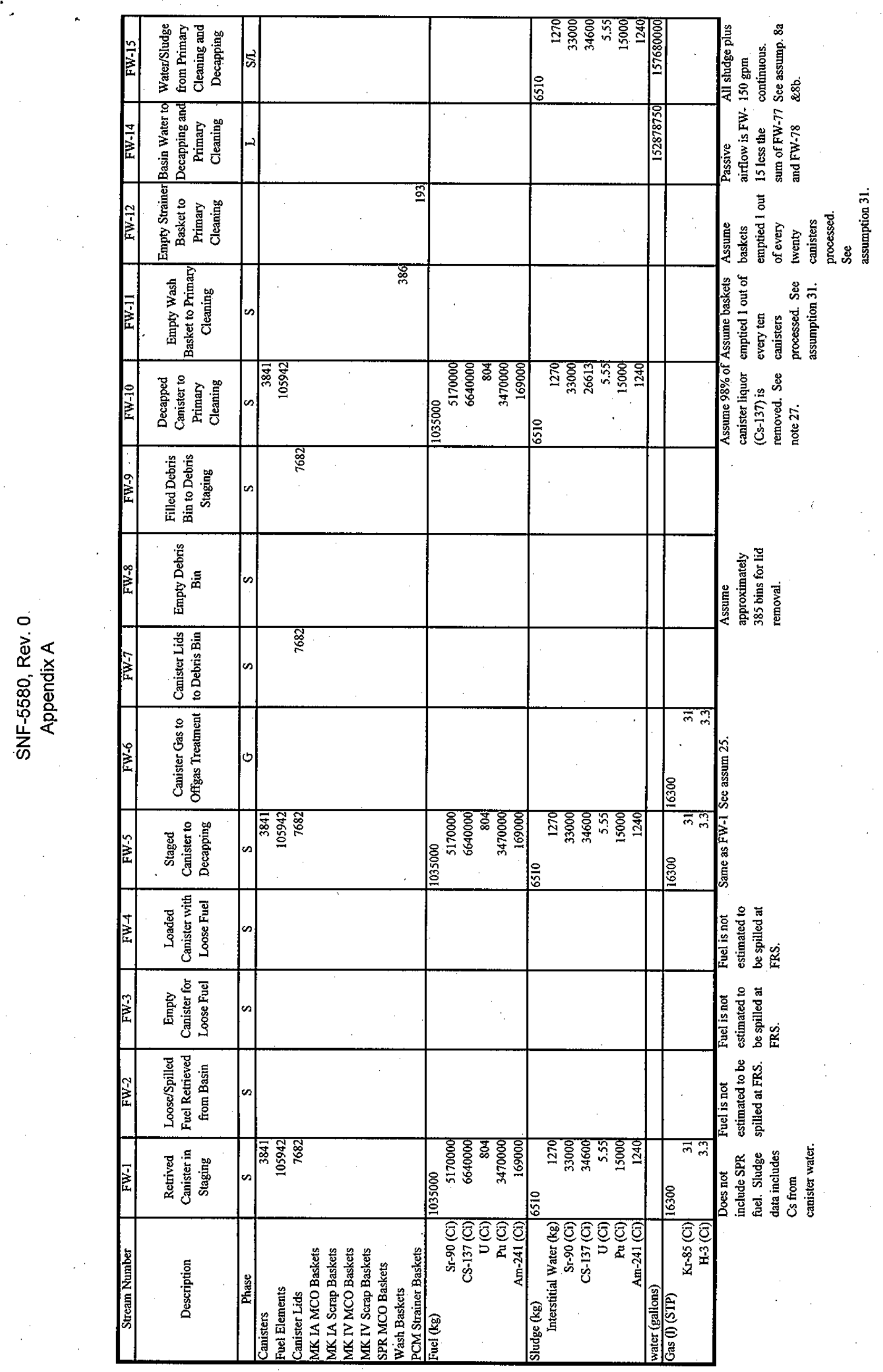




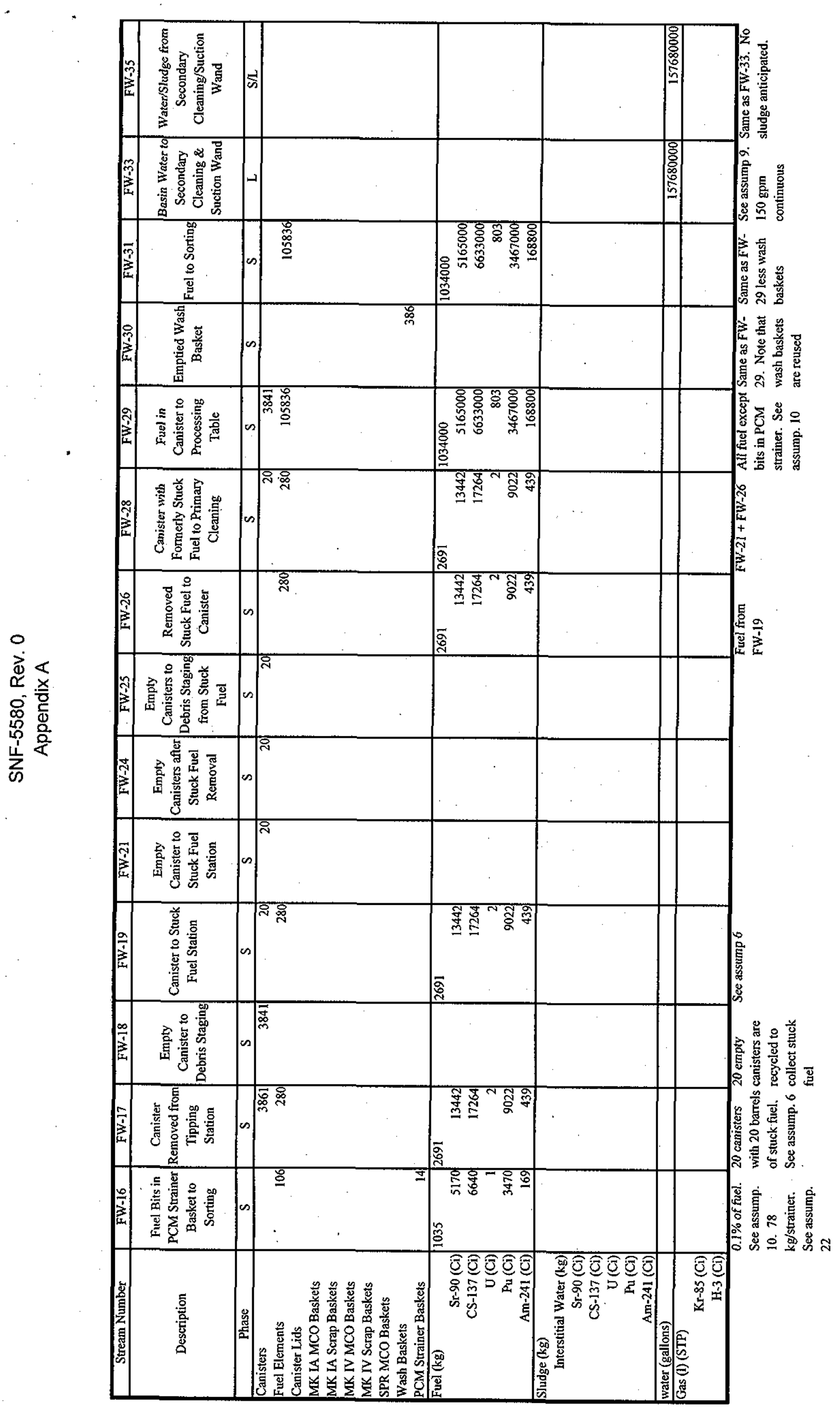

$N$
0
0
0
0 


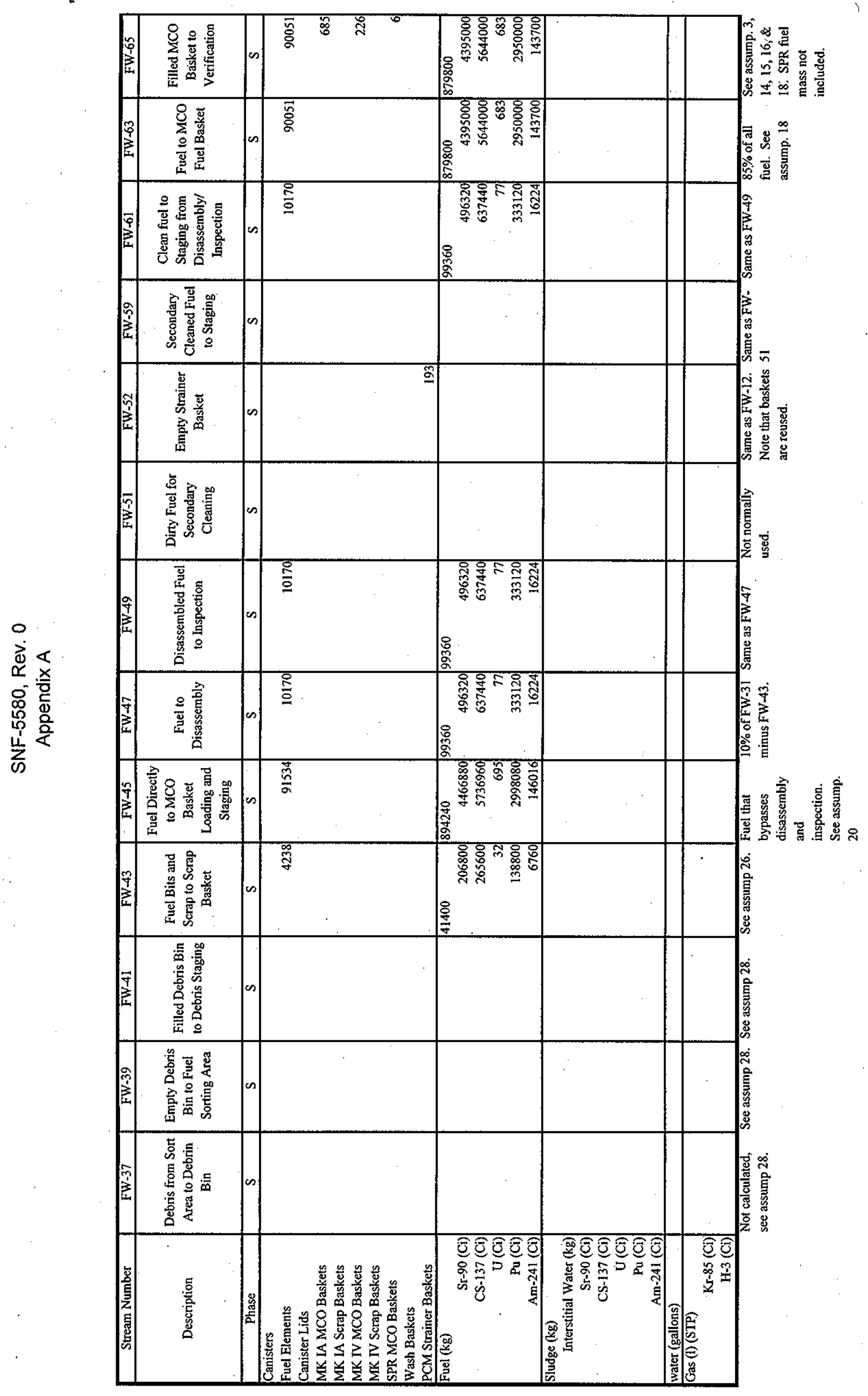

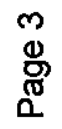




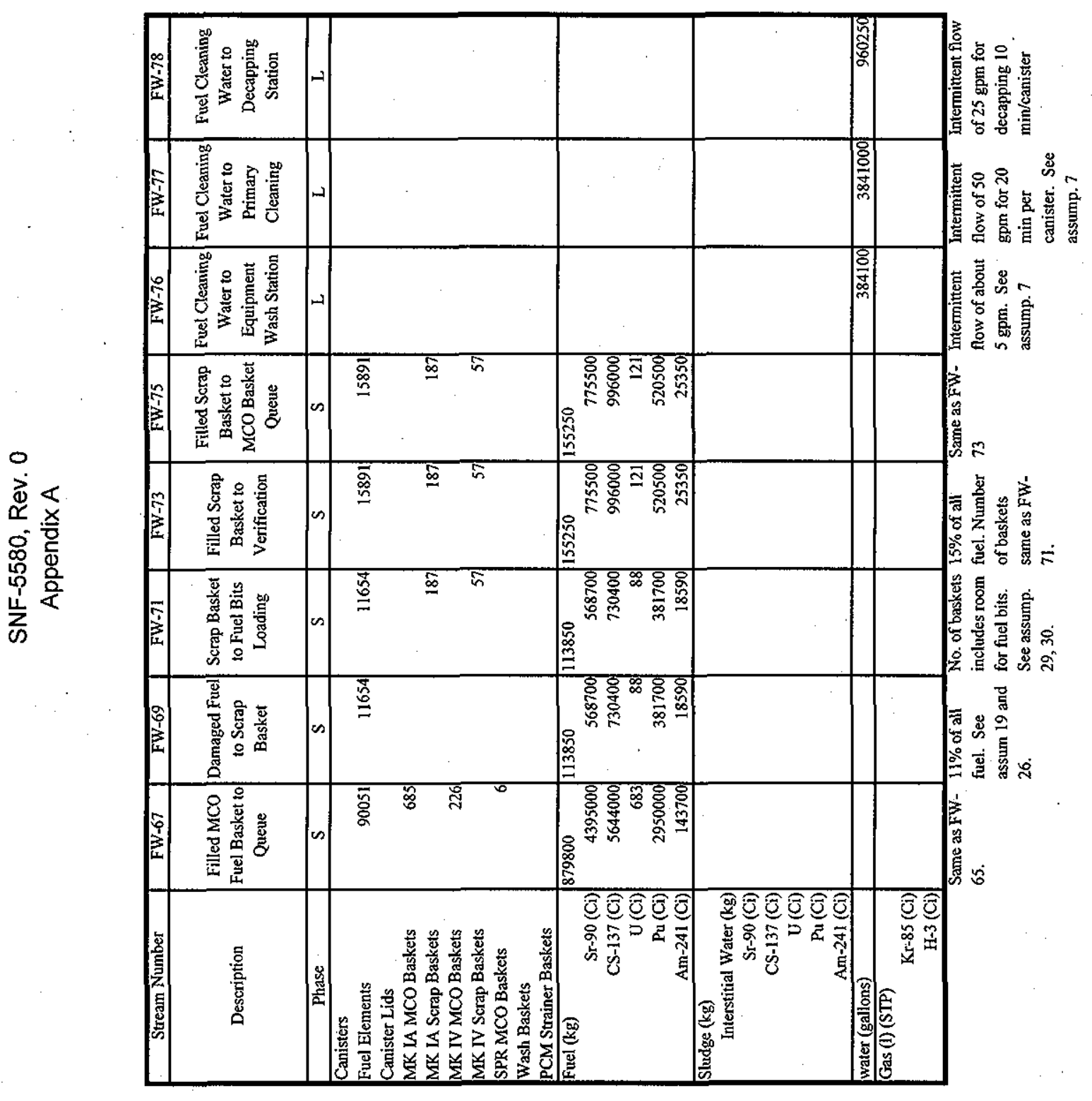



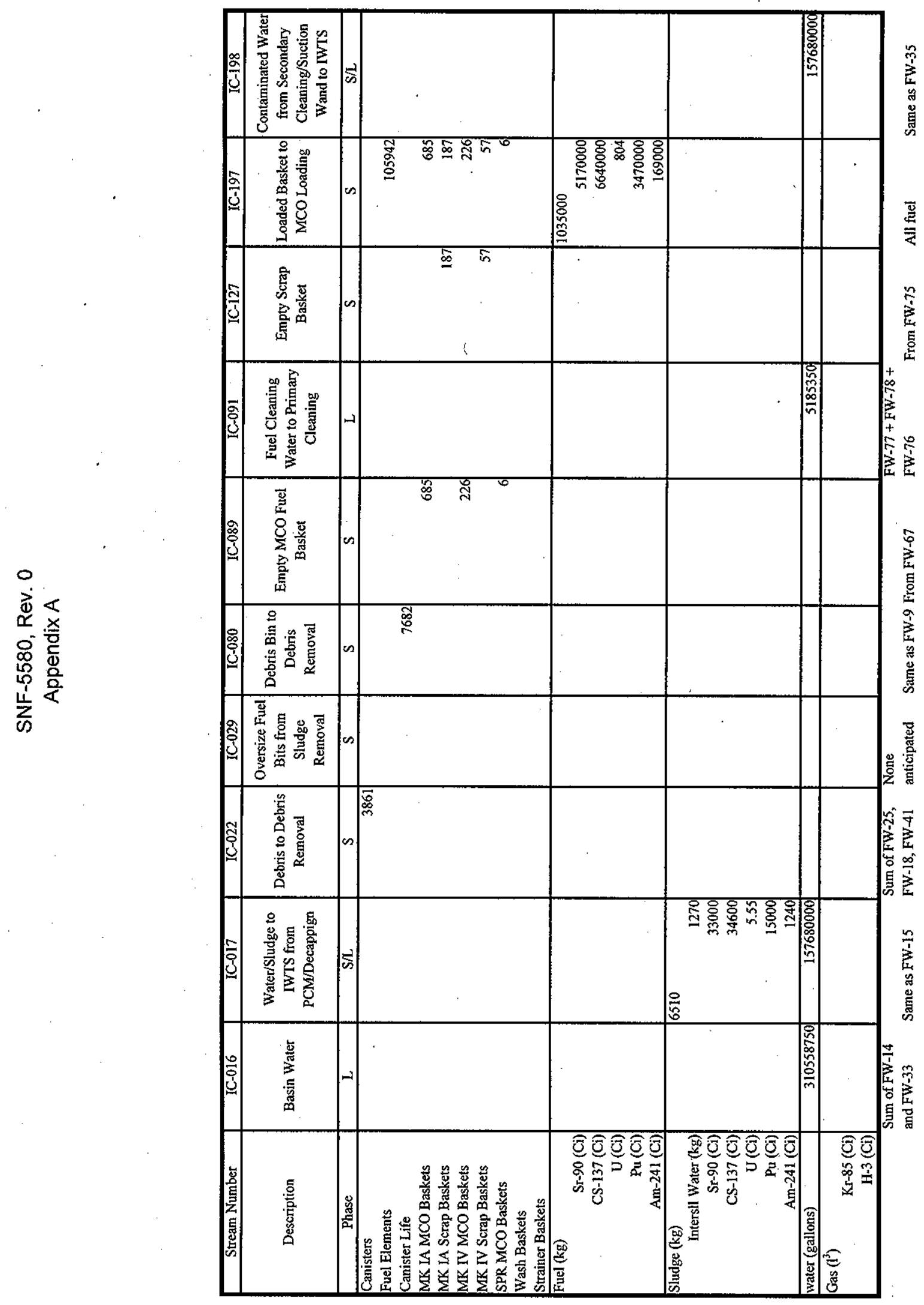

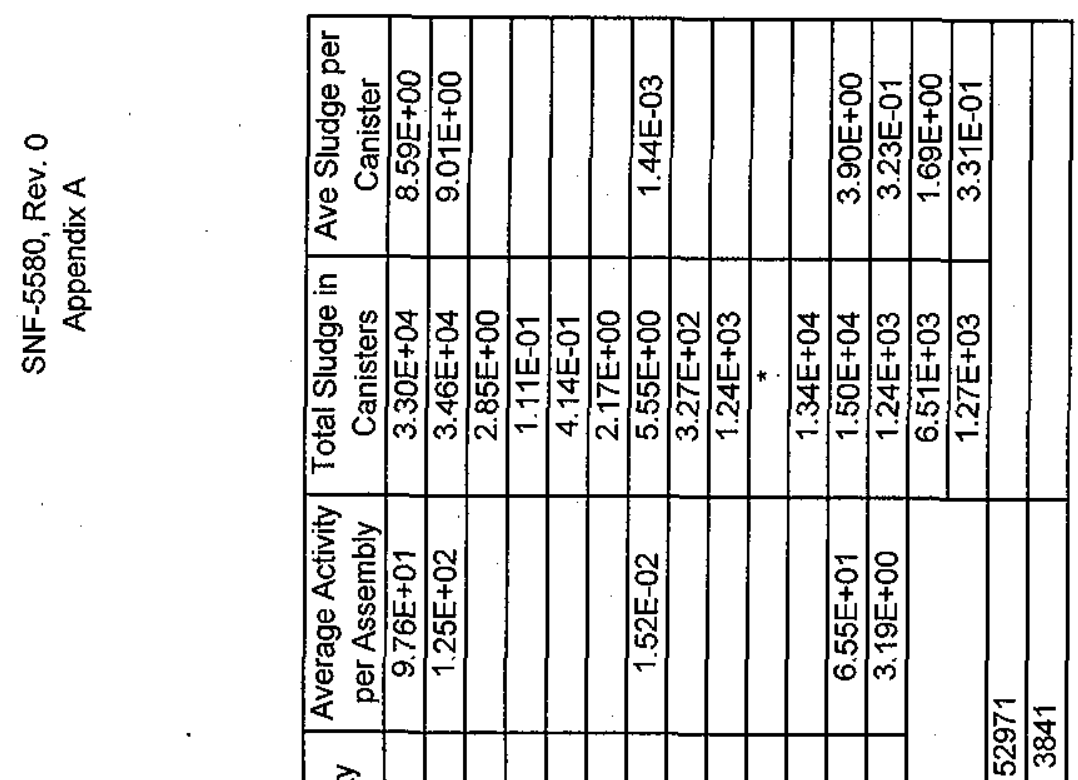

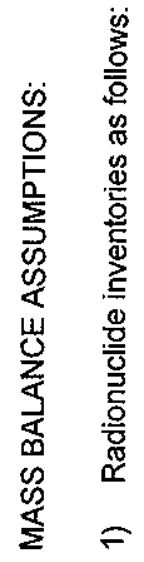

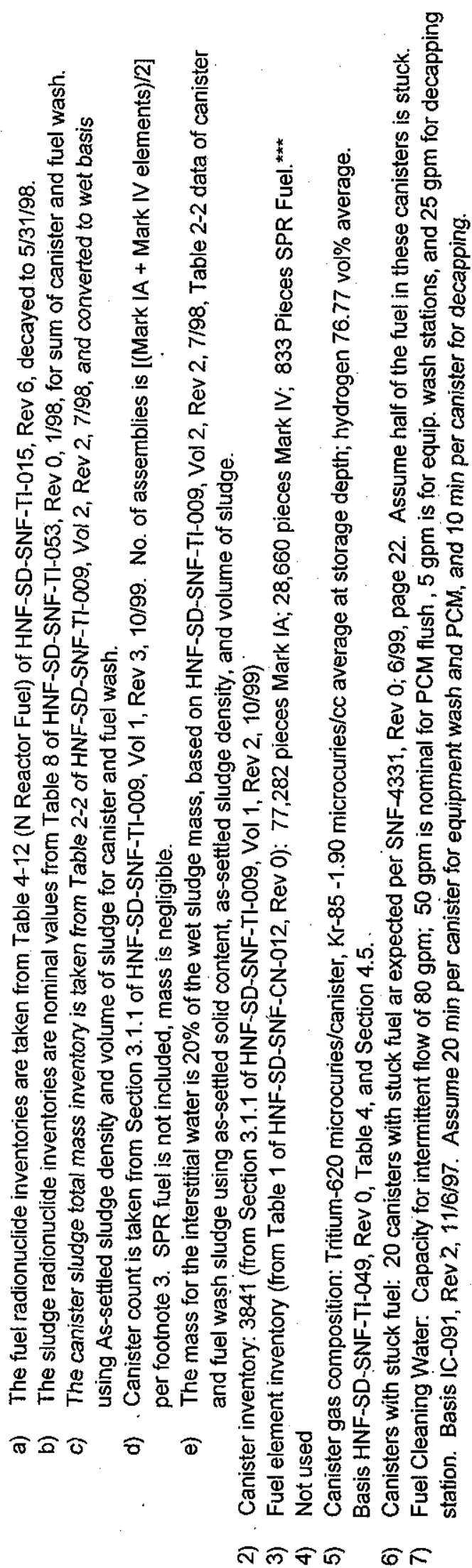




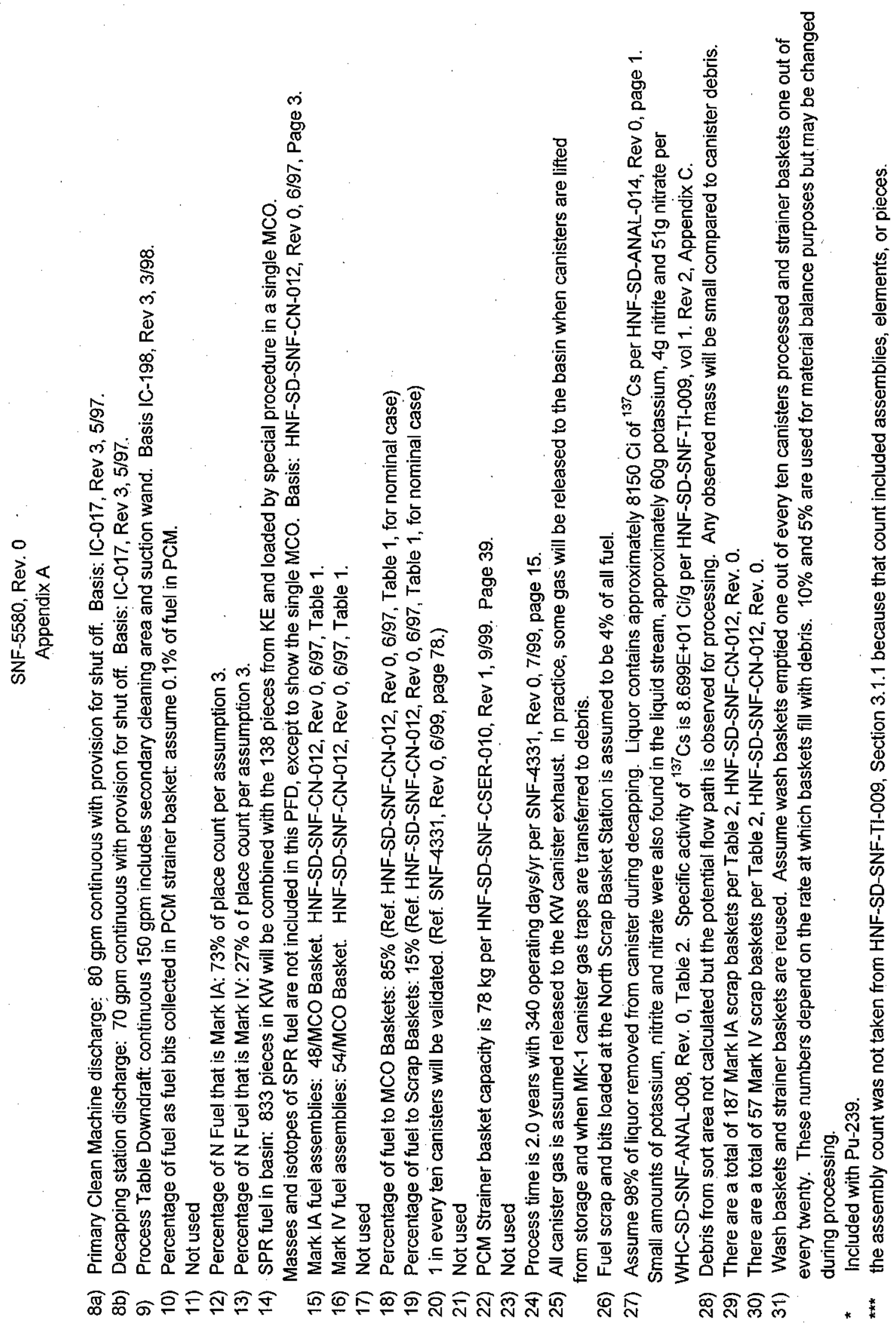


Document Reviewed:

SNF-5580, Fuel Retrieval System process Flow Diagram Mass Balance Calculations

for $K$ West Basin

Scope of Review:

Examined calculations and verified resources for input data and assumptions.

Yes No NA

O $\bigcirc$ * Previous reviews complete and cover analysis, up to scope of this review, with no gaps.

$\bigcirc \bigcirc \quad$ Problem completely defined.

$\bigcirc-\bigcirc \quad$ Accident scenarios developed in a clear and logical manner.

- $\bigcirc \bigcirc$ Necessary assumptions explicitly stated and supported.

$\bigcirc \bigcirc$ Computer codes and data files documented.

- $\bigcirc \quad$ Data used in calculations explicitly stated in document.

- $\bigcirc \quad$ Data checked for consistency with original source information as applicable.

000

Mathematical derivation checked including dimensional consistency of results.

$\bigcirc \bigcirc \quad$ Models appropriate and used within range of validity or use outside range of established validity justified.

- $\bigcirc \quad$ Hand calculations checked for errors. Spreadsheet results should be treated exactly the same as hand calculations.

$\bigcirc \bigcirc$ Software input correct and consistent with document reviewed.

○ $\bigcirc 0$

Software output consistent with input and with results reported in document reviewed.

○ $\mathrm{O}$

Limits/criteria/guidelines applied to analysis results are appropriate and referenced.

Limits/criteria/guidelines checked against references.

(-) $\bigcirc$ Safety margins consistent with good engineering practices.

$\bigcirc \bigcirc$ Conclusions consistent with analytical results and applicable limits.

$\bigcirc \bigcirc$ Results and conclusions address all points required in the problem statement.

- $\bigcirc$ Format consistent with appropriate NRC Regulatory Guide or other standards.

$\bigcirc \bigcirc *$ Review calculations, comments, and/or notes are attached.

○ $\bigcirc$ Document approved.

Heather Boles Neather Toles

Reviewer (Printed Name and Signature)
$12 / 15 / 99$

Date

*Any calculations, comments, or notes generated as part of this review should be signed, dated and attached to this checklist.

Such material should be labeled and recorded in such a manner as to be intelligible to a technically qualified third party. 